\title{
Informed Decision Making Changes Test Preferences for Colorectal Cancer Screen- ing in a Diverse Population
}

\author{
Navkiran K. Shokar, MD, MPH' \\ Carol A. Carlson, BA ${ }^{1}$ \\ Susan C. Weller, $P b D^{1,2}$ \\ 'Department of Family Medicine, Univer- \\ sity of Texas Medical Branch, Galveston, \\ Texas \\ ${ }^{2}$ Department of Preventive Medicine and \\ Community Health, University of Texas \\ Medical Branch, Galveston, Texas
}

\begin{abstract}
PURPOSE We wanted to better understand patient preferences and decision making about options for colorectal cancer screening. Consistency in patient preferences could improve patient-clinician communication about tests by simplifying and focusing discussions.

METHODS In a cross-sectional sample of primary care patients, cognitive ranking tasks were used to estimate patient preferences for fecal occult blood testing, flexible sigmoidoscopy, colonoscopy, and double-contrast barium enema before and after consideration of 13 test attributes, such as accuracy and scientific evidence. Patients also ranked the 13 test attributes and attribute descriptions in terms of importance. Friedman's nonparametric test was used to measure overall discrimination among items, and the average Pearson correlation coefficient $(\bar{r})$ among participants was used to measure the degree of consistency in choices.
\end{abstract}

RESULTS Participants $(n=168$ ) averaged 62.1 years of age, and $64.3 \%$ were of minority racial ethnicity. For test-specific attributes, preferences were for high test accuracy $(\bar{r}=0.63, P<.001)$, amount of colon examined $(\bar{r}=0.64, P<.001)$, strong scientific evidence for efficacy $(\bar{r}=0.59, P<.001)$, minimum discomfort $(\bar{r}=0.50, P<.001)$, and low risk of complications $(\bar{r}=0.38, P<.001)$. When all 13 attributes were considered together, agreement dropped $(\bar{r}=0.13, P<.001)$, but attributes considered most important for decision making were test accuracy, scientific evidence for efficacy, amount of colon examined, and need for sedation. Test preferences showed moderate agreement $(\bar{r}=0.20, P<.001)$, and choices were fairly consistent before and after exposure to test-specific attributes $(\kappa=0.17$, $P=.007)$. Initially the modal choice was fecal occult blood testing (59\%); however, after exposure to test specific attributes, the modal choice was colonoscopy (54\%).

CONCLUSION Participants were clear about the attributes that they prefer, but no single test has those attributes. Preferences were varied across participants and were not predictable; clinicians should discuss the full range of recommended tests for colorectal cancer with all patients.

Ann Fam Med 2010;8:141-150. doi:10.1370/afm.1054

\section{INTRODUCTION}

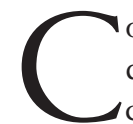
olorectal cancer is the second leading cause of cancer-related deaths in the United States, ${ }_{1}^{1}$ with an estimated 148,810 new cases and 49,960 deaths in $2008 .^{2}$ Professional organizations have widely endorsed screening for colorectal cancer ${ }^{3-5}$ because of evidence of its effectiveness ${ }^{6-11}$ and because screening could prevent 18,800 deaths per year. ${ }^{12}$ Screening remains underutilized, ${ }_{1}^{13-18}$ however, with the lowest rates in African Americans and Hispanics. ${ }^{19-22}$

Discussing colorectal cancer screening is challenging because multiple tests are recommended for screening, the tests are quite different and 
complex, patients lack familiarity with them, physicians have limited time to explain all the tests, and physicians have misconceptions about patient preferences regarding the tests and their attributes. ${ }^{23-26}$ These problems have further been compounded by the continuing evolution of guidelines for colorectal cancer screening. ${ }^{3,4}$ Authoritative guidelines emphasize a shared decision-making approach between the patient and physician in selecting a test. ${ }^{3,4,27}$ Although better patient-clinician communication about colorectal cancer screening offers an opportunity to improve screening rates, ${ }^{28-30}$ to improve rates productively, more information is needed about how patients make screening decisions.

Although previous studies have examined patient preferences ${ }_{,}{ }^{25,31-38}$ more information is needed about the specific attributes of tests that patients prefer. These attributes inform patients choices when a range of options are discussed. This information is of particular importance for minority groups, because they have a higher than average incidence of colorectal cancer and mortality ${ }^{1}$ and lower rates of screening. ${ }^{20,21}$ Furthermore, a demonstrated consistency in patient preferences could improve patient-physician communication about tests by simplifying and focusing the broad array of information available.

The purpose of this study, therefore, was to describe patient test preferences and to identify test attributes that are important in the decision making of diverse patients when 4 recommended colorectal cancer test options are considered together. We used a series of cognitive tasks to better understand the relative importance of test attributes and to examine whether the ranking was consistent across participants and within demographic subgroups. This information could improve physician-patient discussions about screening options and enhance compliance with screening.

\section{METHODS}

In this study, we used data collection techniques that are more typically used in the cognitive sciences and in marketing research. We used detailed, cumulative tasks to explore participants' relative preferences for screening tests for colorectal cancer and their attributes. Because the array of attributes is large and complex, we used a systematic comparative design to estimate patient preferences and to provide an increasing familiarity with the array of attributes. ${ }^{39}$ The purpose was to discover the relative importance of the attributes and desirability of tests when participants chose a screening test and to identify whether choices were consistent among participants or subgroups of participants.

\section{Setting and Participants}

We recruited a cross-sectional sample from a diverse university-based family practice clinic. Inclusion criteria were patients aged 50 years and older of African American, Hispanic, or non-Hispanic white race/ethnicity attending the clinic for a scheduled appointment. We aimed to recruit approximately equal numbers of participants from each racial/ethnic group and sex. Exclusion criteria were a history of malignancy or any advanced medical condition that compromised cognitive ability. The project was approved by the University of Texas Medical Branch Institutional Review Board.

\section{Materials}

We developed a short description for the fecal occult blood test (FOBT), flexible sigmoidoscopy (FS), doublecontrast barium enema (DCBE), and colonoscopy. We then identified the following 13 potentially important test attributes from the literature $25,36,37,40,41$ : test accuracy, amount of colon examined by the test, complications associated with the test, likely out-of-pocket cost for the test, discomfort that may be associated with the test, frequency with which the test is recommended, place of service and the type of clinician performing the test, level of scientific evidence available to support the test, whether there is a need for further testing if the test is positive, whether sedation is needed, type of preparation needed for the test, amount of time the test takes, and the patient's responsibilities for completing the test. We then developed an attribute description for these 13 attributes for each of the 4 tests based on our clinic processes and on findings from literature review. ${ }^{36,42-45}$ For instance, the attribute of accuracy had the following test-specific attribute description: "A. This test can find 24 to 50 of 100 cancers or advanced growths." "B. This test can find 95 of 100 cancers or advanced growths." "C. This test can find 70 to 80 of 100 cancers or advanced growths." "D. This test can find 40 to 50 of 100 cancers or advanced growths." The attribute descriptions did not list the test name, but $\mathrm{A}=\mathrm{FOBT}, \mathrm{B}=$ colonoscopy, $\mathrm{C}=\mathrm{FS}$, and $\mathrm{D}=\mathrm{DCBE}$. Finally, long descriptions of each test were created by combining all 13 attribute descriptions for that test.

Descriptions were refined with pilot testing on 5 participants from each racial/ethnic group $;$ we checked for comprehension of the descriptions and approved the procedure for ranking the tasks.

\section{Procedure}

A trained interviewer identified potentially eligible patients arriving at the clinic for scheduled office visits We assumed that patients make office visits at random, so they were approached consecutively until sample 
sizes were reached for each sex and racial/ethnic subgroup. After eligibility was determined, the trained interviewer obtained informed consent. Participants were interviewed in a private room for about $45 \mathrm{~min}$ utes, during which time the interviewer collected information on sociodemographic characteristics, screening history with any of the tests, family history of colorectal cancer, and the preference data.

In prior work we discovered that patients found it cognitively challenging to process detailed colorectal cancer test information, because they lacked familiarity with the tests and the information is complex. ${ }^{37} \mathrm{We}$ therefore decided on a cumulative exposure approach, using a series of cognitive tasks to collect participants preference data. This approach served to familiarize participants with the test attributes before they indicated their preference. First, participants ranked 4 short descriptions of the screening tests in order of their preference. Second, participants considered each attribute and ranked the attribute descriptions for the 4 tests from 1 to 4 in terms of their importance until all 13 sets of attribute descriptions had been ranked. Ranking the attribute descriptions also served to familiarize participants with the detailed descriptive information. Third, participants ranked the 13 attributes. For this task, they were given a "feeling thermometer" calibrated from 0 to 100 and were asked to place cards on which the 13 attributes were described, along with the thermometer, in order of their importance. Fourth, participants were asked to rank the screening tests in terms of their preference a second time by considering the short description plus the 13 attributes. Tests were compared with paired comparisons, and responses were summed across pairs to produce a rank-ordering for each participant.

\section{Analysis}

We used univariate descriptive statistics to describe sample demographic characteristics. ${ }^{46}$ Preference rankings for the 4 tests using the short descriptions, the 13 sets of attribute descriptions for each test, the 13 attributes, and the 4 tests using the long test descriptions were analyzed for consistency across participants. A reliability analysis on the participants (rather than items) for each ranking task, based on the consistency or agreement (the average correlation coefficient) among participants on their preferences, provided a measure of the reliability of the aggregated ranks across participants. ${ }^{47-49}$ The analysis focused on consistency in the set of ranks provided by the participants and not on the single ranks assigned to any one attribute or test. The average Pearson correlation coefficient calculated between all possible pairs of participants provides a measure of consistency ${ }^{49,50}$ and is directly related to the degree to which the aggregated ranks may reflect shared group values or beliefs independent of sample size. ${ }^{47}$ Friedman's nonparametric inferential test provided the probability level for the discrimination among items. These 2 measures are linked: when agreement is high among participants, the preference for items is distinct. When agreement is low or nonexistent, items do not indicate a clear preference and, in the aggregate, appear to be preferred equally. For analysis, items were ranked from 1 to the number of items in the task. Similar to interrater agreement analysis, a $\kappa$ statistic was used to measure agreement between the initial and final ranking tasks. ${ }^{51}$

Sample size is a function of variation. When examining an array of ranks, sample size is a function of the agreement among participants and the desired level of validity of the aggregated responses. The sample size estimate comes directly from the Spearman-Brown prophesy formula. ${ }^{48,49}$ Validity of the aggregated responses (the correlation, $R$, between the vector of aggregated responses and the true vector of preferences) is the square-root of the reliability coefficient, ${ }^{49}$ and is a function of the number of people rating items $(n)$ and the average interperson correlation coefficient $(\bar{r})^{48}: n=\left[R_{2}(1-\bar{r})\right] /\left[\bar{r}\left(1-R_{2}\right)\right]$. Assuming a moderate level of agreement (an average correlation coefficient between participants' response profiles of $\bar{r}=0.25$ or greater) and high validity (the aggregated responses correlate with the true ordering of items at $R=0.95$ or higher), the minimum sample size needed per group is 28. We over-sampled participants to make subgroup comparisons.

\section{RESULTS}

Of 495 eligible patients approached, 339 (68\%) agreed to participate. Of those agreeing, 179 (53\%) completed the cognitive tasks; the remainder were not able to commit the minimum of 1 hour required to complete the tasks. Five interviews were used for pilot testing and 6 were incomplete, leaving a total of 168 participants for analysis. Because fewer than anticipated Hispanic patients visited the clinic during the study period, we recruited fewer than we hoped; however, our sample size calculations showed the number to be more than sufficient for adequate power. There were no differences in the sex, age, or racial/ethnic composition between the participants and nonparticipants $(P>.05)$. The participants' average age was 62.1 years (range 50 to 79 years), and they were approximately equally divided by race/ethnicity (Table 1 ).

\section{Test Attribute Preferences}

Preference rankings of the attribute descriptions indicated clear and strong preferences for some attributes 


\begin{tabular}{|lcc|}
\hline \multicolumn{2}{l}{ Table 1. Demographic Profile of Study } \\
Participants (N = 168) \\
\hline Characteristic & $\%$ & No. \\
\hline Race/ethnicity & & \\
White & 35.7 & 60 \\
Black & 35.7 & 60 \\
Hispanic & 28.6 & 48 \\
Sex, male & 48.2 & 81 \\
Education & & \\
Less than high school & 10.7 & 18 \\
High school & 41.1 & 69 \\
More than high school & 48.2 & 81 \\
Have health insurance & 88.1 & 148 \\
Past testing & & \\
FOBT & 58.3 & 98 \\
Colonoscopy & 54.8 & 92 \\
Flexible sigmoidoscopy & 30.4 & 51 \\
$\quad$ Barium enema & 35.1 & 59 \\
Family history of colorectal cancer & 11.3 & 19 \\
\hline FOBT = fecal occult blood test. & & \\
\hline
\end{tabular}

(such as accuracy) and less or no preference for others (such as the location of the testing). All of the test attribute descriptions showed a significant discrimination among items $(P<.001)$, and the average Pearson correlation among participants provided an estimate of the amount of agreement. Because the Friedman test parallels an analysis of variance, the effective sample size was not simply the number of participants, but was the number of observations multiplied by the number of conditions (in this case, $168 \times 4=672$ observations). Overall, participants indicated strong, shared preferences for high test accuracy (average Pearson correlation coefficient $\bar{r}=0.63$, reliability coefficient $\left.[\mathrm{rel}]=0.997_{i} P<.001\right)$, the maximum amount of colon examined $(\bar{r}=0.64$, rel $=0.997 ; P<.001)$, scientific evidence for efficacy $(\bar{r}=0.59$, rel $=0.996 ; P<.001)$, low discomfort $(\bar{r}=0.50, \mathrm{rel}=0.995 ; P<.001)$, and little risk of complications $(\bar{r}=0.38, \mathrm{rel}=0.991 ; P<.001)$ (Table 2). Participants also tended to prefer a test with sedation $(\bar{r}=0.20$, rel $=0.97 ; P<.001)$ or one that does not require further testing $(\bar{r}=0.21, \mathrm{rel}=0.978 ; P<.001)$.

Table 2. Specific Attributes of Tests for Colorectal Cancer Screening

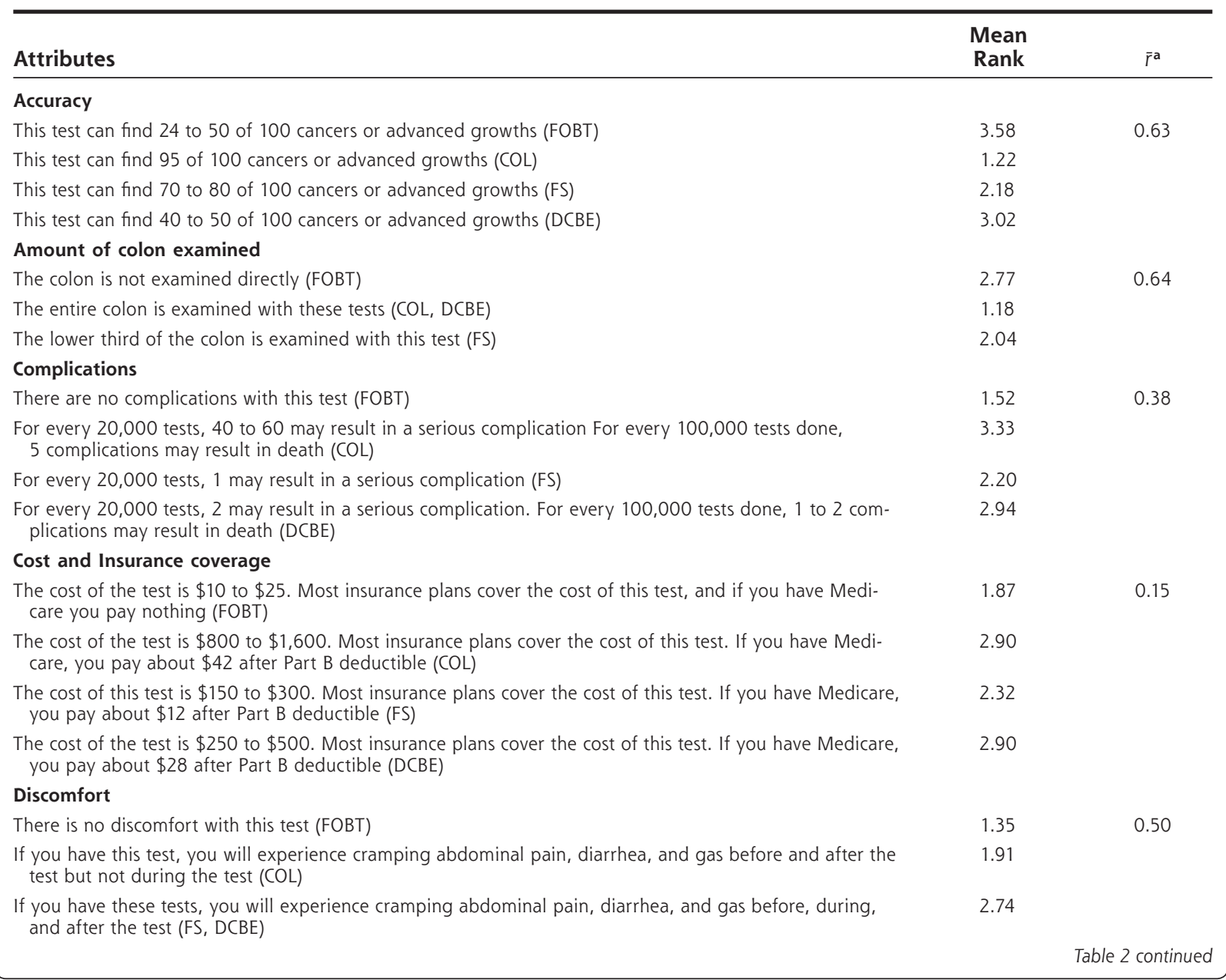


Table 2. Specific Attributes of Tests for Colorectal Cancer Screening (continued)

\begin{tabular}{|c|c|c|}
\hline Attributes & $\begin{array}{l}\text { Mean } \\
\text { Rank }\end{array}$ & $\bar{r}^{\mathrm{a}}$ \\
\hline \multicolumn{3}{|l|}{ Frequency } \\
\hline It is recommended that you have this test done every year (FOBT) & 2.15 & \multirow[t]{4}{*}{0.07} \\
\hline It is recommended that you have this test once every 10 years $(\mathrm{COL})$ & 2.82 & \\
\hline It is recommended that you have this test once every 3 to 5 years (FS) & 2.26 & \\
\hline It is recommended that you have this test once every 5 to 10 years (DCBE) & 2.76 & \\
\hline \multicolumn{3}{|l|}{ Location and person performing test } \\
\hline The test is done by you at home, and a laboratory technician checks the cards (FOBT) & 2.40 & \multirow[t]{4}{*}{0.08} \\
\hline The test is done in the hospital by a physician specialist (COL) & 2.11 & \\
\hline This test can be done by a primary care doctor or a physician specialist in a doctor's office or in a hospital (FS) & 2.45 & \\
\hline This test is done by a radiology technician in a hospital or outpatient facility DCBE) & 3.03 & \\
\hline \multicolumn{3}{|l|}{ Need for further testing } \\
\hline If the test is abnormal, you would need to have another test (COL) to confirm the diagnosis (FOBT, FS, BE) & 1.73 & \multirow[t]{2}{*}{0.21} \\
\hline There is no need for further tests with this test (COL) & 1.27 & \\
\hline \multicolumn{3}{|l|}{ Need for sedation } \\
\hline A shot to make you sleepy will not be given when you have this test (FOBT) & 2.73 & \multirow[t]{4}{*}{0.20} \\
\hline A shot is given to make you sleepy (COL) & 1.81 & \\
\hline A shot to make you sleepy will not be given when you have this test (FS) & 2.73 & \\
\hline A shot to make you sleepy will not be given when you have this test (DCBE) & 2.73 & \\
\hline \multicolumn{3}{|l|}{ Preparation for the test } \\
\hline $\begin{array}{l}\text { For } 5 \text { days before the test, you cannot eat red meat, certain fruits and vegetables, or vitamin C. You can } \\
\text { take your medications (FOBT) }\end{array}$ & 2.36 & \multirow[t]{4}{*}{0.04} \\
\hline $\begin{array}{l}\text { For } 7 \text { days before the test, you can't take aspirin, Motrin, Advil, iron or vitamins. The day before the } \\
\text { test, you can only have a clear liquid diet. The night before this test and between } 5 \text { and } 6 \text { on the } \\
\text { morning of the test, you drink a glass of solution and } 6 \text { to } 8 \text { glasses of clear liquids that cause diar- } \\
\text { rhea, which empties your colon. On the day of the test, you cannot eat breakfast but can take your } \\
\text { medications (COL) }\end{array}$ & 2.77 & \\
\hline $\begin{array}{l}\text { After midnight on the night before the test, you cannot eat or drink anything. One hour before the test, } \\
\text { you need to give yourself } 2 \text { enemas, which cause diarrhea and empty your colon. An enema is when you } \\
\text { place liquid medicine into your bottom. On the day of the test, you cannot eat breakfast but can take } \\
\text { your medications (FS) }\end{array}$ & 2.71 & \\
\hline $\begin{array}{l}\text { The day before the test, you can only have a clear liquid diet. The night before and on the morning of the } \\
\text { test, you drink a solution that causes diarrhea, which empties your colon. On the day of the test, you } \\
\text { cannot eat breakfast but can take your medications (DCBE) }\end{array}$ & 2.16 & \\
\hline \multicolumn{3}{|l|}{ Scientific evidence } \\
\hline $\begin{array}{l}\text { Scientific studies show that having this test regularly in people aged } 50 \text { to } 80 \text { years will reduce the number } \\
\text { of deaths from colon cancer (FOBT) }\end{array}$ & 1.22 & \multirow[t]{3}{*}{0.59} \\
\hline $\begin{array}{l}\text { The scientific evidence is still being evaluated for these tests. There are as yet no studies showing that use } \\
\text { of these tests reduce deaths from colon cancer (COL, DCBE) }\end{array}$ & 2.75 & \\
\hline $\begin{array}{l}\text { Scientific studies suggest that regular testing after the age of } 50 \text { years might reduce deaths from colon } \\
\text { cancer (FS) }\end{array}$ & 2.02 & \\
\hline \multicolumn{3}{|l|}{ Time for test } \\
\hline $\begin{array}{l}\text { Time required for the test is a few minutes on } 3 \text { separate occasions. You will not miss time off from your } \\
\text { regular activities (FOBT) }\end{array}$ & 1.68 & \multirow[t]{3}{*}{0.09} \\
\hline It takes 45 minutes to have this test, but you will need a whole day off from your regular activities (COL) & 2.29 & \\
\hline $\begin{array}{l}\text { It takes about } 30 \text { minutes to have either of these tests. You will need half a day off from your regular } \\
\text { activities (FS, DCBE) }\end{array}$ & 2.03 & \\
\hline \multicolumn{3}{|l|}{ Patient's responsibilities } \\
\hline $\begin{array}{l}\text { When you decide to have this test, you will have to alter your diet, pick up the test kit, put a sample of } \\
\text { your bowel movement on the cards, and mail them or bring them to the laboratory (FOBT) }\end{array}$ & 2.07 & \multirow[t]{4}{*}{0.06} \\
\hline $\begin{array}{l}\text { When you decide to have this test, you will have to alter your diet, make an appointment, buy the solu- } \\
\text { tion, and take the solution at home according to the instructions. You need to bring a responsible adult } \\
\text { who can drive you home (COL) }\end{array}$ & 2.48 & \\
\hline $\begin{array}{l}\text { When you decide to have this test, you will have to alter your diet, make an appointment, buy the enema } \\
\text { solution, and give yourself the enemas at home according to the instructions (FS) }\end{array}$ & 2.82 & \\
\hline $\begin{array}{l}\text { When you decide to have this test, you will have to alter your diet, make an appointment, buy the solu- } \\
\text { tion, and drink it at home according to the instructions (DCBE) }\end{array}$ & 2.63 & \\
\hline
\end{tabular}


Because average agreement levels of 0.25 or greater indicate strong, shared values, ${ }^{47,52}$ the preferences regarding attributes with such high agreement are clear and are shared across participants. Although all ranking tasks showed a significant amount of discrimination (the Friedman test showed that responses were not at random), only high agreement would be interpretable and useful in a clinical setting. Participants wanted the most accurate test (colonoscopy), with the most amount of colon examined (colonoscopy or DCBE), the minimum amount of discomfort (FOBT), the strongest evidence for reducing deaths caused by colon cancer (FOBT), and the smallest risk for complications (FOBT). In contrast, there was much less agreement about the other attributes (Table 2).

We also checked consistency for subgroups of patients to ensure that the low level of overall agreement for the 8 remaining attribute descriptions was not because some subgroups shared preferences that were different from those of other subgroups. Because previous studies indicated lower rates of colorectal cancer screening among those aged 50 to 60 years and minority groups, ${ }^{21,22}$ we examined preferences for the 13 attribute descriptions within each of 6 subgroups formed by age ( 50 to 64 years vs 65 years and older) and race/ethnicity, however, we observed no consistent preference. The agreement levels were low for each attribute and each of the subgroups of patients, indicating that the overall analyses were not masking any subgroup preferences.

When participants considered the relative impor- tance of the 13 attributes together, agreement was moderate $(\bar{r}=0.13$, rel $=.956, P<.001)$. Overall, the top attributes were accuracy of the test, scientific evidence, and the amount of colon examined (Table 3). Within subgroups of participants, these same attributes were considered most important by non-Hispanic whites $(\mathrm{n}=60, \bar{r}=0.21 ; \mathrm{P}<.001)$, Hispanics $(\mathrm{n}=48, \bar{r}=0.11$; $P<.001)$, participants aged between 50 and 64 years $(\mathrm{n}=98, \bar{r}=0.13 ; \mathrm{P}<.001)$, and men $(\mathrm{n}=80, \bar{r}=0.17$; $P<.001)$. Some subgroups varied slightly from this pattern. For example, the African Americans ( $n=60$, $\bar{r}=0.09 ; P<.001)$ ranked accuracy, amount of colon, discomfort, and complications as most important. Patients aged 65 years and older $(\mathrm{n}=70, \bar{r}=0.15, P$ $<.001)$ ranked accuracy, scientific evidence, location of the test, and then amount of colon as important. Female patients $(\mathrm{n}=85, \bar{r}=0.10, P<.001)$ ranked accuracy, scientific evidence, sedation, and then amount of colon as important. The low agreement within these subgroups, however, indicates that the averaged rankings are not reliable estimates of group preferences.

\section{Test Preferences}

To understand preferences for the tests, participants performed an initial ranking task (with short descriptions) before exposure to the detailed test descriptions. This ranking test indicated some consistency in the relative preferences for the 4 tests across participants. There was a preference for the FOBT (rank 1.89), followed by colonoscopy (rank 2.22), FS (rank 2.61), and DCBE (rank 3.28), $(\bar{r}=0.21, \mathrm{rel}=.978 ; P<.001)$. FOBT was the modal first choice of the sample, Table 3. Mean Ranks for Test Attributes by Participants' Race/Ethnicity

\begin{tabular}{|c|c|c|c|c|}
\hline Attributes & $\begin{array}{c}\text { Totala } \\
(\mathrm{N}=168)\end{array}$ & $\begin{array}{l}\text { Non-Hispanic } \\
\text { White }^{b} \\
(n=60)\end{array}$ & $\begin{array}{l}\text { African } \\
\text { Americanc } \\
(n=60)\end{array}$ & $\begin{array}{l}\text { Hispanic }^{d} \\
(n=48)\end{array}$ \\
\hline Accuracy & 4.30 & 3.40 & 4.62 & 5.03 \\
\hline Scientific evidence & 5.31 & 4.72 & 6.16 & 4.99 \\
\hline Amount of colon examined & 5.99 & 5.66 & 6.39 & 5.89 \\
\hline Need for sedation & 6.66 & 6.33 & 7.17 & 6.44 \\
\hline Need for further testing & 6.68 & 6.18 & 6.70 & 7.28 \\
\hline Your responsibilities & 6.92 & 7.29 & 7.02 & 6.32 \\
\hline Complications & 7.02 & 7.83 & 6.58 & 6.55 \\
\hline $\begin{array}{l}\text { Location and who per- } \\
\text { forms the test }\end{array}$ & 7.05 & 6.94 & 7.14 & 7.08 \\
\hline Discomfort & 7.52 & 7.86 & 6.46 & 8.41 \\
\hline Preparation & 7.71 & 8.07 & 7.56 & 7.45 \\
\hline Cost & 8.12 & 8.74 & 7.75 & 7.80 \\
\hline Frequency & 8.35 & 8.18 & 8.38 & 8.52 \\
\hline Time for test & 9.24 & 9.82 & 8.87 & 8.99 \\
\hline \multicolumn{5}{|c|}{$\begin{array}{l}\text { a Reliability }=0.96, \bar{r}=0.13 ; P<.001 . \\
\text { b Reliability }=0.94, \bar{r}=0.21 ; P<.001 . \\
\text { ' Reliability }=0.85, \bar{r}=0.09 ; P<.001 . \\
\text { d Reliability }=0.86, \bar{r}=0.11 ; P<.001 .\end{array}$} \\
\hline
\end{tabular}
chosen by $59 \%$ (100 of 168). There was no association between the participants' first choice for a test and their age, years of education, sex, race/ethnicity, or prior experience with a screening test.

The final ranking task involved ranking the long descriptions of each test (including the short descriptions plus the 13 test attribute descriptions (Table 4). A contingency table comparison of the initial ranking and final ranking showed that many participants changed their initial choice from FOBT to colonoscopy after exposure to the test attribute information. FOBT was the first choice of $59 \%$ of the sample initially, but after exposure to the detailed test attributes, colonoscopy became the modal choice of $54 \%$ (Initial first 


\section{Table 4. Aggregate Test Rankings Before and After Consideration of Attributes}

\begin{tabular}{|c|c|c|}
\hline Short Description & $\begin{array}{l}\text { Ranking } \\
\text { After Short } \\
\text { Description }^{\mathrm{a}}\end{array}$ & $\begin{array}{l}\text { Ranking After Short } \\
\text { Description and all } \\
13 \text { Attributes }\end{array}$ \\
\hline Fecal occult blood testing & 1.89 & 2.60 \\
\hline \multicolumn{3}{|l|}{$\begin{array}{l}\text { This test checks if your bowel movement contains blood. It is done at home using a test kit with } \\
3 \text { cards. You smear a sample of your bowel movement onto a card. This is done for } 3 \text { different } \\
\text { bowel movements. The } 3 \text { cards are then returned to the laboratory }\end{array}$} \\
\hline Colonoscopy & 2.22 & 1.79 \\
\hline \multicolumn{3}{|l|}{$\begin{array}{l}\text { A doctor checks for growths or cancer in your whole colon using a flexible, long, narrow, lighted } \\
\text { tube with a camera on the end. It is inserted into your bottom and then passed into your } \\
\text { whole colon, which can be seen on a television screen. You are given medicine through a } \\
\text { needle in your arm to make you sleepy during the test }\end{array}$} \\
\hline Flexible sigmoidoscopy & 2.61 & 2.46 \\
\hline \multicolumn{3}{|l|}{$\begin{array}{l}\text { A doctor checks for growths or cancer in the lower third of your colon using a short, flexible, } \\
\text { narrow, lighted tube with a camera on the end. It is inserted into your bottom and then } \\
\text { passed only into your lower colon, which can be seen on a television screen. You are awake } \\
\text { during the test }\end{array}$} \\
\hline Double-contrast barium enema & 3.28 & 3.15 \\
\hline $\begin{array}{l}\text { The doctor checks the outline of your colon for growths or cancers. A white liquid called barium } \\
\text { is put into your bottom through a tube by a radiology technician. You must hold the liquid in } \\
\text { while air is also put into your bottom. You are on a table that is moved around and then X-rays } \\
\text { are taken with you in different positions. You are awake during the test }\end{array}$ & & \\
\hline
\end{tabular}

choices: FOBT 59\%, colonoscopy 28\%, FS 8\%, DCBE $5 \%$. Final first choices were colonoscopy $54 \%$, FOBT $26 \%$, FS 13\%, and DCBE 8\%). Nevertheless the choices were fairly stable between the initial and last ranking $(\kappa=0.17 ; P=.007)$. During the final ranking, colonoscopy (rank 1.79) replaced FOBT as the first choice, followed by FS (rank 2.46), FOBT (rank 2.60), and DCBE $($ rank 3.15); $(\bar{r}=0.19$, rel $=0.976 ; P<.001)$. Again, there were no significant associations between participants' first choice and their sociodemographic characteristics. The most preferred test on the final ranking of tests was associated with prior test experience.

\section{DISCUSSION}

The purpose of this study was to better understand test preferences for colorectal cancer screening in a diverse population and to determine whether any consistent patterns could be identified. We observed that when participants were presented with detailed information, their preferences for tests and attributes tended to vary across individuals and subgroups of individuals. Choices were considered in light of their unique experiences and values, and no simple predictions or strong generalizations could have been made. Second, it is not surprising that participants' preferences tended to be for colonoscopy and FOBT, because participants wanted an accurate test with a maximum amount of colon examined, a minimum amount of discomfort, strong evidence for reducing deaths due to colon cancer, and few complications.
Our study design included patients of diverse racial/ ethnic background because they are not often part of studies of preferences for colorectal cancer screening. There was little evidence of systematic patterns within or systematic differences between subgroups, however. It is currently unclear whether the differences we did observe are clinically meaningful and whether this information could be used to tailor the screening discussion to particular subgroups. For instance, although the average rank for colonoscopy was highest, consistency was modest, suggesting disagreement across participants in their order of ranking, with the implication that a single message for everyone may not work. Consistency in preferences for test-specific attribute descriptions was strong and clear, but consistency for tests bordered on a meaningful amount of agreement, and consistency for the 13 attributes considered together only approached a meaningful amount of agreement for some subgroups, eg, non-Hispanic whites, with the implication that a single approach for each subgroup may not work. Clearly, further research is needed to systematically examine these possibilities further.

Although direct comparisons across studies are difficult because of differences in design, methods, and sampling, ${ }^{25,31,33-37,53}$ there are some common themes that emerge. Most studies observe test preferences divided between colonoscopy ${ }^{34,37,53}$ and FOBT. ${ }^{25,31}$ A Canadian study ${ }^{35}$ found computed tomographic colonography, when added to the other tests, to be the most preferred test. Studies consistently find that DCBE is usually the least preferred option when 
included. ${ }^{33,34,37}$ Studies examining subgroup comparisons in test preferences, have conflicting findings: one $^{37}$ found that a higher proportion of African Americans were more likely to prefer colonoscopy, whereas another ${ }^{53}$ found that African Americans were more likely to prefer FS, and Hispanics were more likely than whites to prefer FOBT and DCBE. These findings taken with ours suggest that preferences cannot be reliably predicted by demographic characteristics and may depend on the setting and type of attributes discussed, and suggest a need for presentation of all options and attributes to each patient.

Studies reporting test attribute information tend to include a limited number of attributes, report only the most frequently cited attribute without comparing the relative importance of the attributes, or have simplified the levels of each attribute. ${ }^{25,31,37,53}$ Across these studies, accuracy, frequency, and discomfort tend to be the most commonly included reasons for choosing a test. ${ }^{25,31,37,53}$ Our study identified additional attributes and provides insights about the relative importance of the attributes as well. A finding that needs clarification is the role of cost in decision making. Our study included predominantly insured participants, and the average rank of cost was low in relation to the other attributes. Griffiths et $\mathrm{al}^{33}$ also found that addition of cost information changed the preferences very little, whereas Pignone et $\mathrm{al}^{36}$ found cost considerations changed patient preferences to FOBT.

Guidelines for colorectal cancer screening ${ }^{3,4}$ suggest a shared decision-making approach to counseling for colorectal cancer screening, and this approach has lead to improved outcomes for other conditions. ${ }^{54,55}$ Patient-physician communication about colorectal cancer screening is not often studied, but surveys indicate there may be a mismatch between what physicians discuss and what patients may need. Physicians report offering only 1 type of test and discussing test frequency most often, then comfort, preparation, and procedure ${ }^{56}$; they underestimate the importance of accuracy and overestimate the importance of discomfort. ${ }^{25}$ One implication of our findings is that because preferences were not consistent across participants, the counseling process for colorectal cancer screening should include all tests, and physicians could focus on FOBT, colonoscopy, and test operating characteristics, such as accuracy, scientific evidence base, and amount of colon examined. Primary care consultations offer little time for such counseling, however, ${ }^{57,58}$ and lack of time is a major barrier to shared decision making. ${ }^{49}$ In our study, it took a trained interviewer at least 45 minutes to review information and elicit preferences. Clearly, new strategies to ameliorate this problem need to be developed. We were constricted in our ability to examine the effect of prior screening type on initial or final colorectal cancer test preferences, because relatively few participants had undergone only one type of test. Previous testing experience could certainly influence screening test preferences, and exploring these experiences offers a strategy for busy clinicians to identify quickly barriers to testing and offer more-specific communication about screening tests that could save time. Other potential strategies include the use of decision aids to help with informed decision making.

Our study provides a broad and deep understanding about patient preferences for colorectal cancer screening. In previous work we discovered that patients found it cognitively challenging to process detailed test information about colorectal cancer screening before making an informed decision. ${ }^{37} \mathrm{~A}$ strength of the current study design was the cumulative experience with the attributes; participants were first familiarized with the range of properties for each attribute (attribute description), the attributes were then assessed relative to one another, and finally the attributes were organized by test and were considered together. This process ensured that participants were better able to make a considered decision about the tests at the end. Another strength is that we examined a triethnic sample of patients and were able to compare preferences within and across these groups. The study is limited, however, in generalizability, because participants were predominantly insured and recruited from a single clinic. Another limitation is that our materials did not include some newer procedures (computed tomographic colonography, or fecal-based DNA tests), ${ }^{3}$ although our study remains consistent with the 2008 US Preventive Services Task Force recommendations ${ }^{4}$ that continue to recommend FOBT, FS, or colonoscopy and emphasize the role of shared decision making, but do not recommend these newer tests because of insufficient evidence.

Based on our study findings, clinicians should discuss with all patients the full array of available tests screening tests for colorectal cancer, and discussions should focus on describing characteristics related to accuracy rather than process, because accuracy is what patients identify as most important for decision making

To read or post commentaries in response to this article, see it online at http://www.annfammed.org/cgi/content/full/8/2/141.

Key words: Colorectal neoplasms; mass screening; physician-patient communication; patient preference; decision making; ethnic groups

Submitted December 5, 2008; submitted, revised, May 18, 2009; accepted June 24, 2009.

Funding support: This research was supported by a grant from a joint American Academy of Family Physicians and American Academy of Family Physicians Foundation Grant Awards Program, NCI K07 CA107052A1. 
Acknowledgments: We would like to thank Alma Salazar and Kristal Gilford for assistance with data collection.

\section{References}

1. Ries $L$, Wingo $P$, Miller $D$, et al. The annual report to the nation on the status of cancer, 1973-1997, with a special section on colorectal cancer. Am Cancer Soc. 2000;88:2398-2424

2. American Cancer Society. Cancer Facts and Figures, 2008. http:// www.cancer.org/downloads/STT/2008CAFFfinalsecured.pdf.

3. Levin B, Lieberman DA, McFarland B, et al. American Cancer Society Colorectal Cancer Advisory Group. US Multi-Society Task Force. American College of Radiology Colon Cancer Committee. Screening and surveillance for the early detection of colorectal cancer and adenomatous polyps, 2008: a joint guideline from the American Cancer Society, the US Multi-Society Task Force on Colorectal Cancer, and the American College of Radiology. CA Cancer J Clin. 2008;58(3):130-160

4. Whitlock E, Lin J, Liles E, Beil T, Fu R. Screening for colorectal cancer: a targeted, updated systematic review for the U.S. Preventive Services Task Force. Ann Intern Med. 2008;149(9):638-658 \& W117-W122.

5. Zoorob R, Anderson R, Cefalu C, Sidani M. Cancer screening guidelines. Am Fam Physician. 2001;63(6):1101-1112.

6. Hardcastle JD, Chamberlain JO, Robinson MH, et al. Randomised controlled trial of faecal-occult-blood screening for colorectal cancer. Lancet. 1996;348(9040):1472-1477.

7. Kronborg O, Fenger C, Olsen J, Jørgensen OD, Søndergaard O. Randomised study of screening for colorectal cancer with faecal-occultblood test. Lancet. 1996;348(9040):1467-1471.

8. Mandel JS, Bond JH, Church TR, et al. Reducing mortality from colorectal cancer by screening for fecal occult blood. Minnesota Colon Cancer Control Study. N Engl J Med. 1993;328(19):1365-1371.

9. Müller AD, Sonnenberg A. Protection by endoscopy against death from colorectal cancer. A case-control study among veterans. Arch Intern Med. 1995;155(16):1741-1748.

10. Selby JV, Friedman GD, Quesenberry CP Jr, Weiss NS. A case-control study of screening sigmoidoscopy and mortality from colorectal cancer. N Engl J Med. 1992;326(10):653-657.

11. Winawer SJ, Flehinger BJ, Schottenfeld D, Miller DG. Screening for colorectal cancer with fecal occult blood testing and sigmoidoscopy. J Natl Cancer Inst. 1993;85(16):1311-1318.

12. Maciosek MV, Solberg LI, Coffield AB, Edwards NM, Goodman MJ. Colorectal cancer screening: health impact and cost effectiveness. Am J Prev Med. 2006;31(1):80-89.

13. Anderson LM, May DS. Has the use of cervical, breast, and colorectal cancer screening increased in the United States? Am J Public Health. 1995;85(6):840-842.

14. Breen N, Wagener DK, Brown ML, Davis WW, Ballard-Barbash $R$. Progress in cancer screening over a decade: results of cancer screening from the 1987, 1992, and 1998 National Health Interview Surveys. J Natl Cancer Inst. 2001;93(22):1704-1713.

15. Ruffin MT IV, Gorenflo DW, Woodman B. Predictors of screening for breast, cervical, colorectal, and prostatic cancer among community-based primary care practices. J Am Board Fam Pract. 2000;13(1):1-10.

16. Seeff L, Nadel M, Blackman D; Centers for Disease Control and Prevention (CDC). Colorectal cancer test use among persons aged $>$ or $=50$ years - United States, 2001. MMWR Morb Mortal Wkly Rep. 2003;52(10):193-196.

17. Smith RA, Cokkinides V, Eyre HJ. American Cancer Society guidelines for the early detection of cancer, 2006. CA Cancer J Clin. 2006;56(1):11-25, quiz 49-50.
18. US Department of Health and Human Services. Healthy People 2010, Conference Edition, Section 3-12. http://www.health.gov/ healthypeople. Accessed Jan 2000.

19. Special section: colorectal cancer and early detection. In: Cancer Facts and Figures. Atlanta, GA: American Cancer Society; 2002:20-27.

20. Shapiro JA, Seeff LC, Thompson TD, Nadel MR, Klabunde CN Vernon SW. Colorectal cancer test use from the 2005 National Health Interview Survey. Cancer Epidemiol Biomarkers Prev. 2008;17(7):1623-1630.

21. Shokar NK, Carlson CA, Weller SC. Prevalence of colorectal cance testing and screening in a multiethnic primary care population. J Community Health. 2007;32(5):311-323.

22. Swan J, Breen N, Coates RJ, Rimer BK, Lee NC. Progress in cancer screening practices in the United States: results from the 2000 National Health Interview Survey. Cancer. 2003;97(6):1528-1540.

23. Cooper G, Fortinsky R, Hapke R, Landefeld C. Factors Associated with the use of flexible sigmoidoscopy as a screening test for the detection of colorectal carcinoma by primary care physicians. Cancer. 1998:1476-1481.

24. Hawley ST, Levin B, Vernon SW. Colorectal cancer screening by primary care physicians in two medical care organizations. Cancer Detect Prev. 2001;25(3):309-318.

25. Ling BS, Moskowitz MA, Wachs D, Pearson B, Schroy PCl. Attitudes toward colorectal cancer screening tests. J Gen Intern Med. 2001;16(12):822-830

26. Schroy PC III, Geller AC, Crosier Wood M, et al. Utilization of colorectal cancer screening tests: a 1997 survey of Massachusetts internists. Prev Med. 2001;33(5):381-391.

27. Pignone M, Rich M, Teutsch SM, Berg AO, Lohr KN. Screening for colorectal cancer in adults at average risk: a summary of the evidence for the U.S. Preventive Services Task Force. Ann Intern Med. 2002;137(2):132-141.

28. Greiner KA, Engelman KK, Hall MA, Ellerbeck EF. Barriers to colorectal cancer screening in rural primary care. Prev Med. 2004; 38(3):269-275

29. Katz M, James A, Pignone $M$, et al. Colorectal cancer screening among African American church members: A qualitative and quantitative study of patient-provider communication. BMC Public Health 2004;4(62):1-8

30. Tessaro I, Magone C, Pawar V. Knowledge, barriers, and predictors of colorectal cancer screening in an Appalachian church population. Prev Chronic Dis. 2006;3(4):1-11.

31. DeBourcy AC, Lichtenberger S, Felton S, Butterfield KT, Ahnen DJ, Denberg TD. Community-based preferences for stool cards versus colonoscopy in colorectal cancer screening. J Gen Intern Med. 2008;23(2):169-174.

32. Frew E, Wolstenholme J, Whynes D. Mass population screening for colorectal cancer: factors influencing subjects' choice of screening test. J Health Serv Res Policy. 2001;6(2):85-91.

33. Griffith JM, Lewis CL, Brenner AR, Pignone MP. The effect of offering different numbers of colorectal cancer screening test options in a decision aid: a pilot randomized trial. BMC Med Inform Decis Mak. 2008;8:4.

34. Leard LE, Savides TJ, Ganiats TG. Patient preferences for colorectal cancer screening. J Fam Pract. 1997;45(3):211-218.

35. Marshall DA, Johnson FR, Phillips KA, Marshall JK, Thabane L, Kulin NA. Measuring patient preferences for colorectal cancer screening using a choice-format survey. Value Health. 2007;10(5):415-430.

36. Pignone M, Bucholtz D, Harris R. Patient preferences for colon cancer screening. J Gen Intern Med. 1999;14(7):432-437.

37. Schroy PC III, Lal S, Glick JT, Robinson PA, Zamor P, Heeren TC. Patient preferences for colorectal cancer screening: how does stool DNA testing fare? Am J Manag Care. 2007;13(7):393-400. 
38. Wolf AM, Schorling JB. Does informed consent alter elderly patients' preferences for colorectal cancer screening? Results of a randomized trial. J Gen Intern Med. 2000;15(1):24-30.

39. Gagne RM. The acquisition of knowledge. Psychol Rev. 1962;69:355-365.

40. Salkeld GP, Solomon MJ, Short L, Ward J. Measuring the importance of attributes that influence consumer attitudes to colorectal cancer screening. ANZ J Surg. 2003;73(3):128-132.

41. Shokar N, Weller S, Vernon S. Cancer and Colorectal Cancer: Knowledge, beliefs and Screening Preferences of a Diverse Population. Fam Med. 2005;31(5):341-347

42. Centers for Disease Control. Screen for Life. http://www.cdc.gov/ cancer/screenforlife. Accessed Jan 3, 2005.

43. American Society for Gastrointestinal Endoscopy. Common Complication of Colonoscopy. http://www.asge.org/nspages/practice/ patientcare/complications.cfm. Accessed Jan 3, 2005.

44. Lieberman DA, Weiss DG, Bond JH, Ahnen DJ, Garewal H, Chejfec $\mathrm{G}$. Use of colonoscopy to screen asymptomatic adults for colorectal cancer. Veterans Affairs Cooperative Study Group 380. N Engl J Med. 2000;343(3):162-168.

45. Blakeborough A, Sheridan MB, Chapman AH. Complications of barium enema examinations: a survey of UK Consultant Radiologists 1992 to 1994. Clin Radiol. 1997;52(2):142-148.

46. SPSS for Windows [computer software]. Release 14.0.1. Chicago, IL: SPSS, Inc; 2001.

47. Weller S. Cultural consensus theory: Applications and frequently asked questions. Field Meth. 2007;19(4):339-368.

48. Weller S, Romney A. Systematic Data Collection. Qualitative Research Methods Series 10. Vol 10. Thousand Oaks, CA: Sage Publications; 1988.
49. Nunnally J. Psychometric Theory. New York, NY: McGraw Hill; 1978.

50. Zajonc R. A note on group judgement and group size. Hum Relat. 1962;15(2):117-180.

51. Fleiss J. Statistical Methods For Rates and Proportions. Malden, MA: Wiley Interscience; 1981;150.

52. Weller SC, Mann NC. Assessing rater performance without a "gold standard" using consensus theory. Med Decis Making. 1997;17(1):71-79.

53. Hawley ST, Volk RJ, Krishnamurthy P, Jibaja-Weiss M, Vernon SW, Kneuper S. Preferences for colorectal cancer screening among racially/ethnically diverse primary care patients. Med Care. 2008;46(9)(Suppl 1):S10-S16.

54. Hack TF, Degner LF, Watson P, Sinha L. Do patients benefit from participating in medical decision making? Longitudinal follow-up of women with breast cancer. Psychooncology. 2006;15(1):9-19.

55. Street RL Jr, Voigt B. Patient participation in deciding breast cancer treatment and subsequent quality of life. Med Decis Making. 1997;17(3):298-306.

56. Wolf MS, Baker DW, Makoul G. Physician-patient communication about colorectal cancer screening. J Gen Intern Med. 2007;22(11):1493-1499.

57. Stange KC, Zyzanski SJ, Jaén CR, et al. Illuminating the 'black box'. A description of 4454 patient visits to 138 family physicians. J Fam Pract. 1998;46(5):377-389.

58. Stange KC, Flocke SA, Goodwin MA. Opportunistic preventive services delivery. Are time limitations and patient satisfaction barriers? J Fam Pract. 1998;46(5):419-424. 